\title{
Determination of the sediment thickness on the heat-exchange surfaces by free vibration method
}

\author{
$E V$ Izmaylova $^{1, *}, E V$ Garnyishova $^{1}, R B$ Kazakov $^{2}$ and $V V$ Serov $^{3}$ \\ ${ }^{1}$ Kazan State Power Engineering University, 51, Krasnoselskaya st., Kazan, Russia \\ ${ }^{2}$ SE «Kazakov R.B.», 105/74, Dekabristov st., Kazan, Russia \\ ${ }^{3}$ LLC «TAIF-NK AZS», 5/19, Astronomicheskaya st., Kazan, Russia
}

\begin{abstract}
Sediments on the heat exchangers surfaces reduce the heat transfer coefficient and heat exchange efficiency, and lead to significant energy losses. The paper discusses the method of express control of the sediment thickness on heat-exchange surfaces. The method is based on the analysis of attenuation of free oscillations parameters of the controlled product. Studies were conducted on models of the heat-exchange equipment surface, namely steel plates of $400 \mathrm{~mm}$ long, $160 \mathrm{~mm}$ wide and $2 \mathrm{~mm}$ thick, with different sediments thicknesses of $0,1.0,1.5,2.0,2.5 \mathrm{~mm}$. The Wilcoxon's rank sum test was used to determine the dynamics of the spectra changes. Studies have shown that the free vibration method allows one to determine not only the presence of deposits on the heat-exchange surfaces, but also their thicknesses.
\end{abstract}

\section{Introduction}

In heat supply systems, the sediments formed on the heating surfaces of heat exchangers are referred to lowtemperature. The main components of such sediments are silicates, calcium carbonates, as well as iron oxides and calcium sulfates.

The coefficient of thermal conductivity of scale is $0.1-2.0 \mathrm{~W} /(\mathrm{m} \mathrm{K})$ [1]. Since the thermal conductivity of sediments is low, even a small layer of these sediments creates a large thermal resistance. In addition to reducing heat transfer, the deposition of scale on the wall leads to an increase in the temperature of the heat exchanger surface. Usage of contaminated heat exchangers in heat supply systems result in an increase in coolant flow rate and an increase in temperature in the reverse pipeline. This causes an increase in pump power consumption and heat losses in pipelines [2]. To restore the design mode of operation, the heat exchangers must be taken out of operation and the contaminated surfaces must be cleaned.

For the purpose of timely cleaning of heating surfaces from sediments, it is necessary to have an accessible method for monitoring the sediments thickness. Widespread ultrasonic thickness gauges cannot solve the problem. It happens because the structural heterogeneity of the sediments leads to a high attenuation of the ultrasonic signal with a significant level of structural interference making it difficult to perform measurements.

The research objective is assessment of the possibility of sediments control on the heat-exchange surfaces by free damped oscillations. Thickness determination should be performed from the outside of the heat-exchange surface during operation.

\section{Methods}

Sound, ultra- and infrasound control methods, collectively referred to as acoustic methods, for determining the strength, elastic, plastic and viscous properties of materials are widely used in the production and operation of materials and products $[3,4]$. Acoustic control methods are based on the measurement of physical parameters associated with the phenomenon of elastic waves diffusion in a solid. The basis of lowfrequency control methods is the correlation between the elastic constants of the material and the physicalmechanical properties of the products [5-7]. Free vibration method is based on the initiation of free elastic oscillations of wide frequency range in the controlled area of the product and the registration of the spectra changes of the received signals in the defective areas compared with the spectra observed in benign areas. The spectrum of the initiated impulses largely depends on the elastic properties and other parameters of the tested product, as well as on the parameters of the initiating oscillation of the electromagnetic device. The frequency range of the spectra of defective and benign zones of products, usually controlled by the free vibration method, is in the range of $0.5-20 \mathrm{kHz}$. Vibrations obtaining is carried out using a piezoelectric receiver or a microphone $[8,9]$. 


\section{Attenuation of free oscillations as a diagnostic feature}

The following equation is used to describe the damped oscillations (1)

$$
x(t)=A_{0} \cdot e^{-n t} \cdot \sin \left(\omega \cdot t+\varphi_{0}\right),
$$

where $A_{0}$ is the initial amplitude of free oscillations; $\varphi_{0}$ is the initial phase; $\omega$ is the circular frequency; $n$ is the attenuation coefficient determining the speed of amplitude change.

$A_{0}$ and $\varphi_{0}$ are determined by the initial conditions, and the cyclic frequency of damped oscillations is equal to:

$$
\omega=\sqrt{\omega_{0}^{2}-n^{2}}
$$

The graph of damped oscillations is an amplitudemodulated sinusoid (Fig. 1). The modulating function (the exponent) characterizes the amplitude decrease over time $[10,11]$ :

$$
A(t)=A_{0} \cdot e^{-n t}
$$

Experimental evaluation of free vibrations attenuation can be performed in several ways:

- By signal,

- By signal scanning spectra,

- Indirectly.

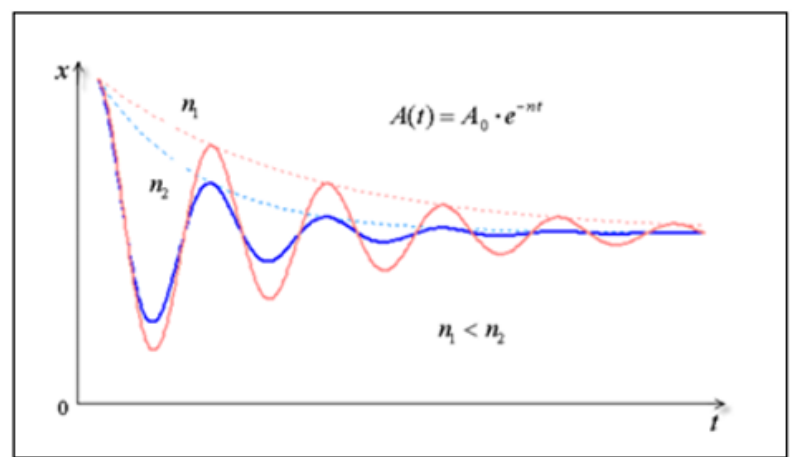

Fig. 1. Damped oscillations.

Evaluation of free vibrations attenuation by signal is reduced to finding the appropriate envelope of the signal graph. Two other methods are related to the calculation of the signal scanning spectra. By scanning a signal, we mean the process of moving along the time axis with a constant step of a fixed size window. The signal samples that fell into the window in one or another of its positions on the time axis are used to form a signal sample (selection) to form a spectrum along it. During shaping the spectrum, one can use the known windowweighting functions of the digital signal samples (Bartlett window, Hamming window, etc.) $[12,13]$. Each scan spectrum can be associated with a specific time. After scanning, we get the dependence of the signal spectrum on time. Fig. 2 shows the result of a signal scan. Here it is easy to notice the attenuation of all frequency components of the signal.

The oscillations' attenuation obtained from the change in a statistical criterion calculated for each of the signal scanning spectra will be further called as an indirect evaluation of the oscillations' attenuation.

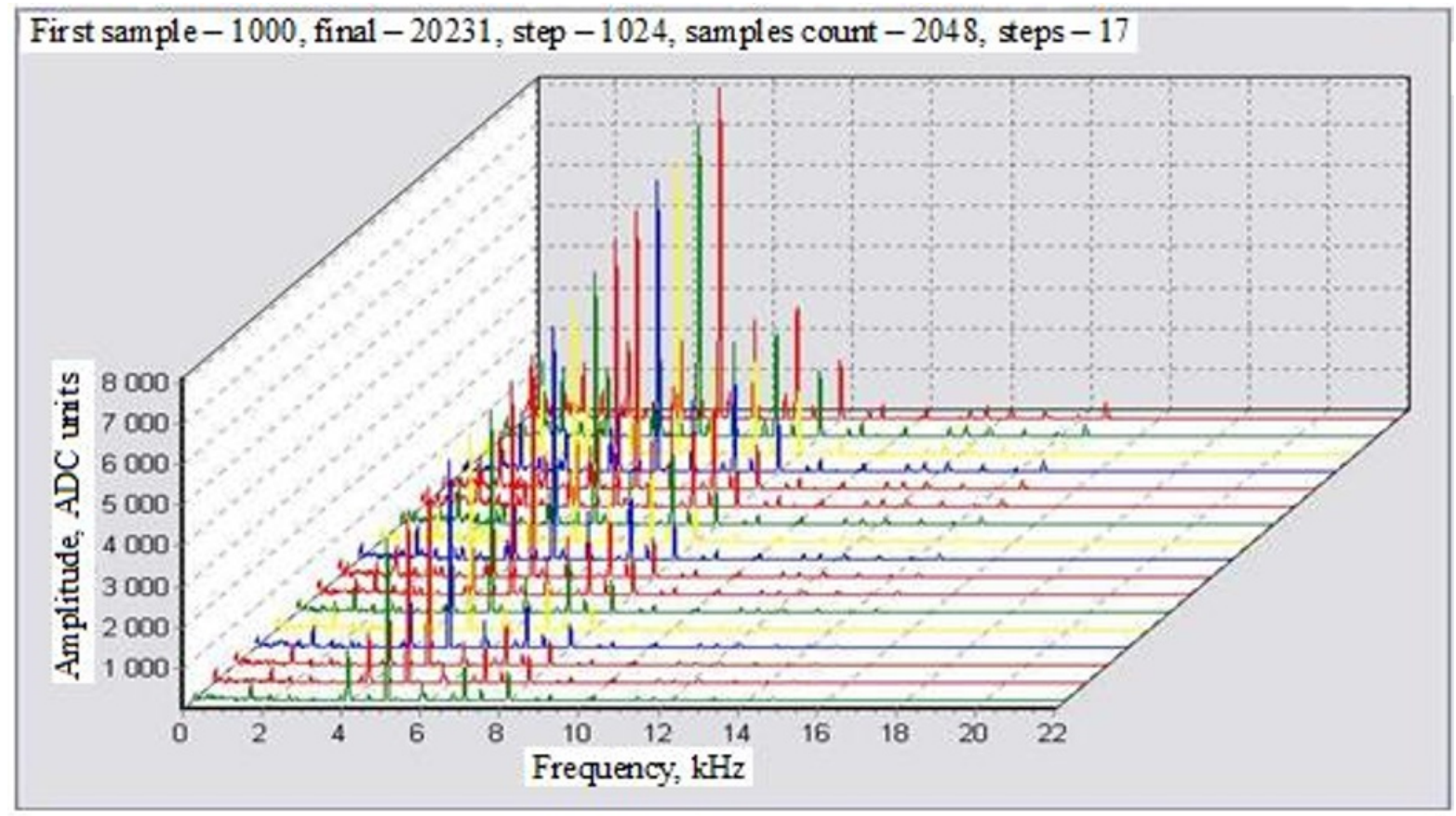

Fig. 2. A set of signal scanning spectra. The time axis is directed to the reader. 


\section{Objects and methods of research}

As a model of the heat-exchange equipment surface, a steel plate of $400 \mathrm{~mm}$ long, $160 \mathrm{~mm}$ wide and $2 \mathrm{~mm}$ thick was used. A mechanical hit was applied to the plate and the amplitudefrequency characteristics of the response were measured by a microphone. Next, a layer of carbonate sediments was put on the research surface and the measurements were repeated. Plates with thicknesses of $1,1.5,2.0,2.5 \mathrm{~mm}$ were investigated. Ten experiments were carried out with each type of plate.

The block scheme of the stand for research is shown in Fig. 3.

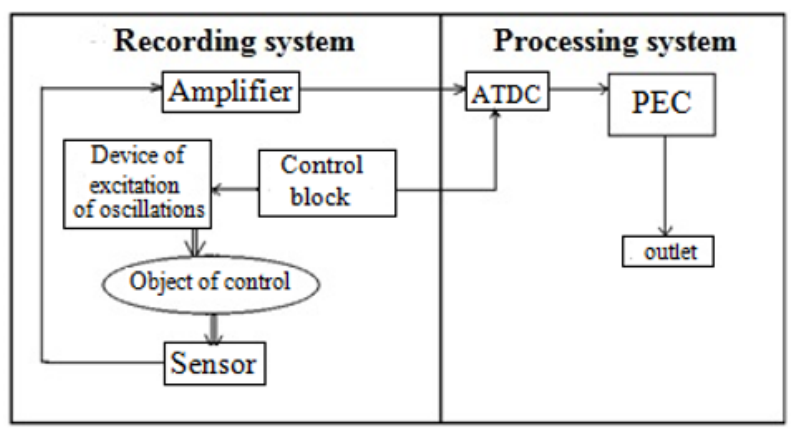

Fig. 3. Block scheme of the measuring stand.

\section{Discussion of results}

Fig. 4 shows an example of the recorded signal and its amplitude spectrum. Fig. 5 shows an example of the current spectrum, the reference one and the difference between them.

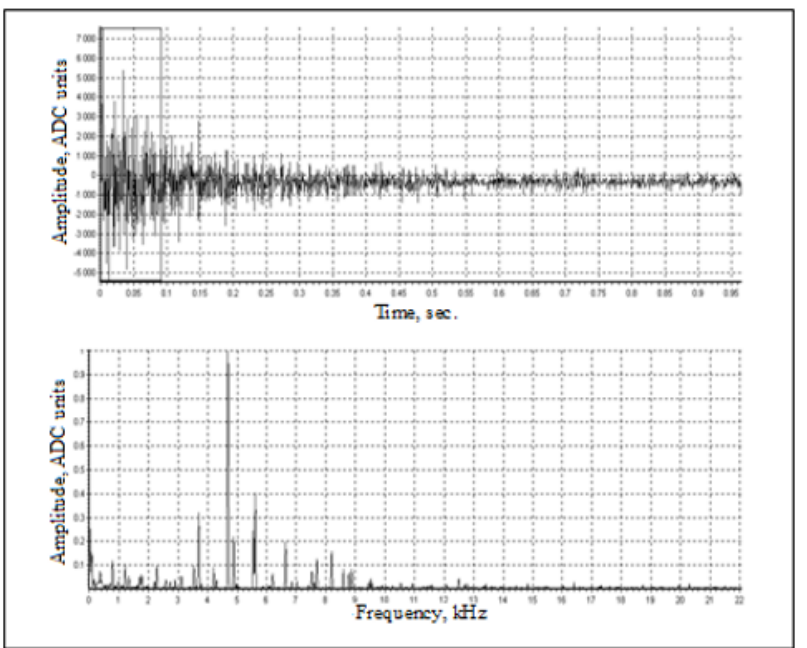

Fig. 4. Signal and its amplitude spectrum.

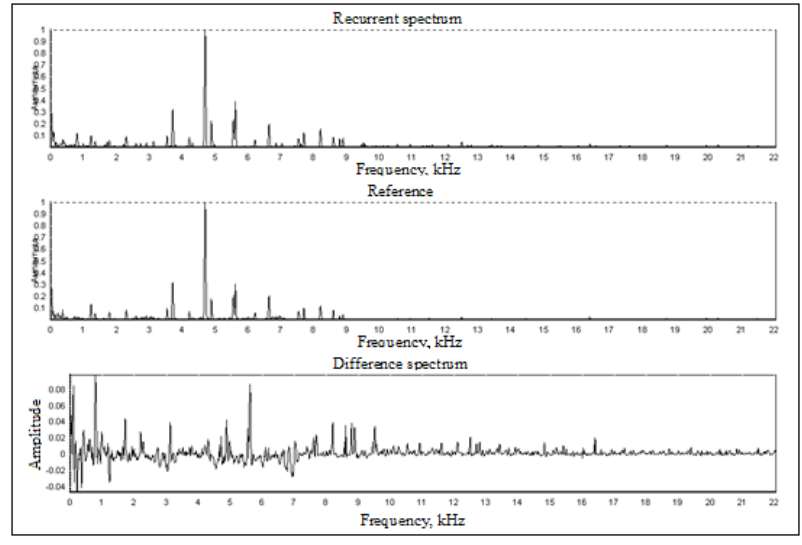

Fig. 5. An example of the current spectrum, the reference one and the difference between them.

The Wilcoxon's rank sum test was used to determine the dynamics of changes in the spectra. It is nonparametric statistical method, which is used for evaluation the differences between two selections by the level of any trait measured quantitatively. This method of identifying differences between selections was proposed in 1945 by Frank Wilcoxon (F. Wilcoxon) [14, 15]. The results of changes in statistics for nine spectra of scanning signals of a clean plate and plates with sediment are shown in Table 1 and in Fig. 6. The first spectrum from each scan series was taken as the reference spectrum.

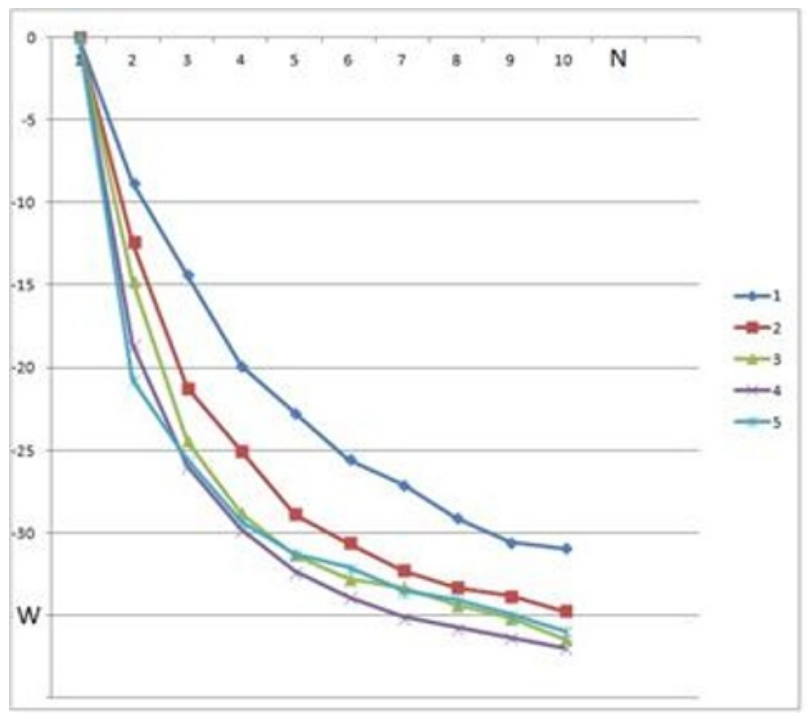

Fig. 6. The time change in Wilcoxon statistics for the studied signal spectra: 1 - Clean plate, $2-1.0 \mathrm{~mm}$ sediment thickness, $3-1.5 \mathrm{~mm}$ sediment thickness, $4-2.0 \mathrm{~mm}$ sediment thickness, $5-2.5 \mathrm{~mm}$ sediment thickness.

The equations of polynomial approximation of the third degree with the approximation accuracy of $\mathrm{R}^{2}$ were obtained in Excel according to the results presented in Table 1.

$$
\begin{array}{ll}
Y_{1}=-0.0433 x^{3}+1.1428 x^{2}-11.215 x+9.8658 & R^{2}=0.9987 \\
Y_{2}=-0.0954 x^{3}+2.11934 x^{2}-17.382 x+14.789 & R^{2}=0.9974 \\
Y_{3}=-0.1437 x^{3}+3.0649 x^{2}-21.817 x+18.307 & R^{2}=0.9967
\end{array}
$$


Table 1. Wilcoxon statistics values for samples scanning spectra.

\begin{tabular}{|c|c|c|c|c|c|}
\hline Scan spectrum number & \multicolumn{5}{|c|}{ Wilcoxon statistics values (W) } \\
\hline & $\begin{array}{c}\text { sample without } \\
\text { sediment }\end{array}$ & $\begin{array}{c}\mathbf{1} \text { mm sediment } \\
\text { thickness }\end{array}$ & $\begin{array}{c}\mathbf{1 . 5} \mathbf{~ m m} \\
\text { sediment } \\
\text { thickness }\end{array}$ & $\begin{array}{c}\mathbf{2 . 0} \mathbf{~ m m} \\
\text { sediment } \\
\text { thickness }\end{array}$ & $\begin{array}{c}\mathbf{2 . 5} \mathbf{~ m m} \\
\text { sediment } \\
\text { thickness }\end{array}$ \\
\hline $\mathbf{1}$ & 0 & 0 & 0 & 0 & 0 \\
\hline $\mathbf{2}$ & -8.802 & -12.414 & -14.748 & -18.594 & -20.729 \\
\hline $\mathbf{3}$ & -14.391 & -21.228 & -24.453 & -25.939 & -25.599 \\
\hline $\mathbf{4}$ & -19.886 & -25.038 & -28.806 & -29.79 & -29.303 \\
\hline $\mathbf{5}$ & -22.741 & -28.852 & -31.341 & -32.333 & -31.245 \\
\hline $\mathbf{6}$ & -25.546 & -30.608 & -32.796 & -33.885 & -32.074 \\
\hline $\mathbf{7}$ & -27.103 & -32.265 & -33.316 & -35.079 & -33.501 \\
\hline $\mathbf{8}$ & -29.092 & -33.286 & -34.36 & -35.736 & -34.027 \\
\hline $\mathbf{9}$ & -30.585 & -33.823 & -35.181 & -36.311 & -34.944 \\
\hline
\end{tabular}

$\begin{array}{ll}\mathrm{Y}_{4}=-0.1511 \mathrm{x}^{3}+3.2118 \mathrm{x}^{2}-22.537 \mathrm{x}+17.743 & \mathrm{R}^{2}=0.9845 \\ \mathrm{Y}_{5}=-0.1698 \mathrm{x}^{3}+3.4629 \mathrm{x}^{2}-23.092 \mathrm{x}+17.321 & \mathrm{R}^{2}=0.9664\end{array}$

\section{Conclusion}

The performed studies have shown the fundamental possibility of using the free vibrations method to detect and evaluate the sediment thickness on the heatexchange surfaces. Usage of non-parametric ranking criteria when comparing signal spectra allows detecting a sediment layer in a fraction of a millimeter.

\section{References}

1. E.R. Saifullin, Yu.V. Vankov, E.V. Izmaylova, E.R. Bazukova, Method of assessing the thermal state of the heat transfer surfaces, Journal of Physics: Conference Series, Low-temperature Plasma during the Deposition of Functional Coatings. "Scientific Technical Conference on Low Temperature Plasma during the Deposition of Functional Coatings, LTP Coatings, 012-058 (2018)

2. O.L. Danilov, A.B. Garyayev, I.V. Yakovlev, Eds. A.V. Klimenko, Energy saving in power engineering and heat technologies. Textbook for universities (2010)

3. N.P. Aleshin, Methods of acoustic control of metals (1989)

4. I.N. Yermolov, N.P. Aleshin, A.I. Potapov, Nondestructive control. Book 2. Acoustic methods of control, 283

5. Yu.V. Vankov, Sh.G. Ziganshin, E.V. Izmailova, A.R. Zagretdinov, The effect of the size and position of transverse cracks in the natural frequencies of the rods, IOP Conference Series: Materials Science and Engineering Ser. "International Scientific and Technical Conference "Innovative Mechanical Engineering Technologies, Equipment and Materials-2014", ISC IMETEM 2014, 012-036 (2015)

6. A.R. Zagretdinov, Y.V. Vankov, I.V. Ivshin, The Analysis of Frequencies of Own Insulators
Fluctuations for the Solution of a Problem of their Control, 2nd International Conference on Industrial Engineering, ICIE-2016, Chelyabinsk; Russian Federation, 150, 2334-2339 (2016)

7. Yu.V. Vankov, Sh.G. Ziganshin, E.V. Izmailova, V.V. Serov, Determination of the oscillation frequencies of corrosion defects finite element methods in order to develop methods of acoustic monitoring of pipelines, IOP Conference Series: Materials Science and Engineering (2015)

8. Yu.V. Vankov, Sh.G. Ziganshin, E.V. Izmailova, Monitoring the technical condition of pipelines by acoustic methods, 160 (2015)

9. Yu.V. Vankov, Low-frequency control methods. The method of free oscillations, (2003)

10. A.A. Detlaf, B.M. Yavorsky, Course of Physics (1999)

11. Yu.V. Vankov, E.R. Yakovleva, About one approach to estimating the damping of oscillations, Technical acoustics, 5, 251-265 (2005)

12. S.L. Marple, Digital spectral analysis with applications (2007)

13. D.E. Newland, An Introduction to Random Vibrations, Spectral \& Wavelet Analysis Third Edition (2005)

14. H.B. Mann, D.R. Whitney, On a test of whether one of two random variables is stochastically larger than the other, Annals of Mathematical Statistics, 18, 5060 (1947)

15. F. Wilcoxon, Individual Comparisons by Ranking Methods, Biometrics Bulletin, 1, 80-83 (1945) 